JiSEA
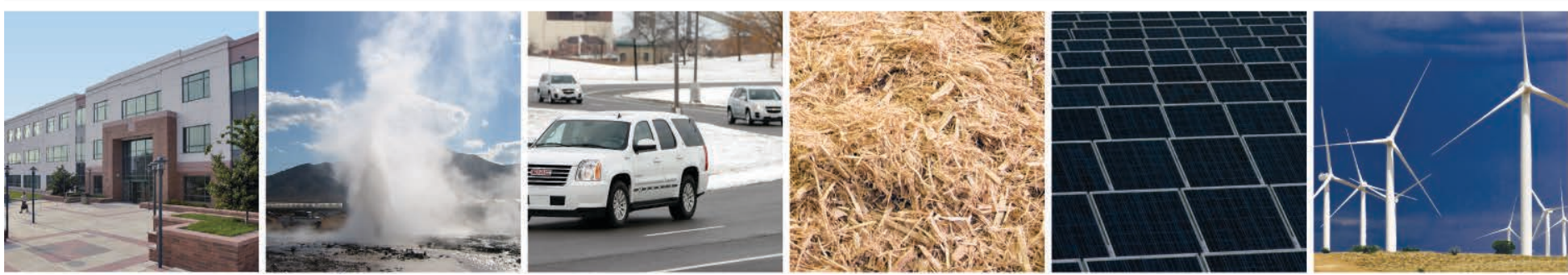

\title{
Executive Summary - Natural Gas and the Transformation of the U.S. Energy Sector: Electricity
}

Jeffrey Logan, Garvin Heath, and Jordan Macknick National Renewable Energy Laboratory

Elizabeth Paranhos and William Boyd University of Colorado Law School

Ken Carlson

Colorado State University

The Joint Institute for Strategic Energy Analysis is operated by the Alliance for Sustainable Energy, LLC, on behalf of the U.S. Department of Energy's National Renewable Energy Laboratory, the University of Colorado-Boulder, the Colorado School of Mines, the Colorado State University, the Massachusetts Institute of Technology, and Stanford University.

Technical Report

NREL/TP-6A50-57702

January 2013

Contract No. DE-AC36-08G028308 


\title{
Executive Summary - Natural Gas and the Transformation of the U.S. Energy Sector: Electricity
}

\author{
Jeffrey Logan, Garvin Heath, and
} Jordan Macknick

National Renewable Energy Laboratory

Elizabeth Paranhos and William Boyd University of Colorado Law School

Ken Carlson

Colorado State University

Prepared under Task No. WWJI.1010

The Joint Institute for Strategic Energy Analysis 15013 Denver West Parkway Golden, CO 80401 303-275-3000 • www.jisea.org
The Joint Institute for Strategic Energy Analysis is operated by the Alliance for Sustainable Energy, LLC, on behalf of the U.S. Department of Energy's National Renewable Energy Laboratory, the University of Colorado-Boulder, the Colorado School of Mines, the Colorado State University, the Massachusetts Institute of Technology, and Stanford University.

JISEA $^{\circledR}$ and all JISEA-based marks are trademarks or registered trademarks of the Alliance for Sustainable Energy, LLC.

\section{Technical Report}

NREL/TP-6A50-57702

January 2013

Contract No. DE-AC36-08GO28308 


\section{NOTICE}

This report was prepared by the Joint Institute for Strategic Energy Analysis and funded by its corporate sponsors. The Joint Institute for Strategic Energy Analysis is operated by the Alliance for Sustainable Energy, LLC, on behalf of the U.S. Department of Energy's National Renewable Energy Laboratory, the University of Colorado-Boulder, the Colorado School of Mines, the Colorado State University, the Massachusetts Institute of Technology, and Stanford University. Neither the United States government nor any agency thereof, nor any of their employees, makes any warranty, express or implied, or assumes any legal liability or responsibility for the accuracy, completeness, or usefulness of any information, apparatus, product, or process disclosed, or represents that its use would not infringe privately owned rights. Reference herein to any specific commercial product, process, or service by trade name, trademark, manufacturer, or otherwise does not necessarily constitute or imply its endorsement, recommendation, or favoring by the United States government or any agency thereof. The views and opinions of authors expressed herein do not necessarily state or reflect those of the United States government or any agency thereof.

Available electronically at http://www.osti.gov/bridge

Available for a processing fee to U.S. Department of Energy and its contractors, in paper, from:

U.S. Department of Energy

Office of Scientific and Technical Information

P.O. Box 62

Oak Ridge, TN 37831-0062

phone: 865.576 .8401

fax: 865.576 .5728

email: mailto:reports@adonis.osti.gov

Available for sale to the public, in paper, from:

U.S. Department of Commerce

National Technical Information Service

5285 Port Royal Road

Springfield, VA 22161

phone: 800.553 .6847

fax: 703.605.6900

email: orders@ntis.fedworld.gov

online ordering: http://www.ntis.gov/help/ordermethods.aspx

Cover Photos: (left to right) PIX 12721, PIX 13995, @ GM Corp., PIX 16161, PIX 15539, PIX 16701

Printed on paper containing at least $50 \%$ wastepaper, including $10 \%$ post consumer waste. 


\section{About JISEA}

The Joint Institute for Strategic Energy Analysis (JISEA) conducts interdisciplinary researchrealized through teams drawn from the founding partners and a network of national and global affiliates - and provides objective and credible data, tools, and analysis to guide global energy investment and policy decisions. JISEA is focused on providing leading analysis; guiding decisions on energy, investment, and policy; and answering questions that enable a cost-effective transition to sustainable energy at significant speed and scale, while minimizing unintended impacts.

JISEA is operated by the Alliance for Sustainable Energy, LLC, on behalf of the U.S.

Department of Energy's National Renewable Energy Laboratory (NREL), the University of Colorado-Boulder, the Colorado School of Mines, the Colorado State University, the Massachusetts Institute of Technology, and Stanford University. Each institution brings a unique set of capabilities to the partnership.

Learn more at JISEA.org. 


\section{Foreword}

We are very pleased to present this work on natural gas and the transformation of the United States' power sector. The subject is both highly topical and divisive. Very few people saw the dramatic changes coming that are being witnessed in the U.S. natural gas sector. The critical role of unconventional gas - and specifically, shale gas - has been dramatic. The changes taking place in the U.S. natural gas sector go well beyond the boundaries of traditional energy-sector analysis. They touch on areas as diverse as foreign policy and industrial competitiveness.

This makes the topic ripe for robust analytical work, which is the role of the Joint Institute for Strategic Energy Analysis (JISEA).

To help inform both the national and international dialogue on this subject, we have focused on a few key areas critical to decision makers. These issues include greenhouse gas emissions, regulatory interventions, water management, and the portfolio of generation in the power sector.

As part of our series of studies on the U.S. energy system, this body of work continues to elucidate details related to life cycle greenhouse gas emissions of shale gas relative to other options for power generation. It also contributes new analysis related to water and regulatory frameworks that are evolving apace. Additionally, we evaluate various pathways for the evolution of the electric sector given a range of options for natural gas, other technologies, and policy.

Although the four principal areas of focus in this report are closely interrelated, each has its own specific needs in terms of analysis, investment risk, and policy design. We have presented detailed consideration of each area, with further appended supporting material, to contribute to the ongoing and increasing national and international dialogue.

We hope you enjoy the report and find the results and discussion useful for your work.

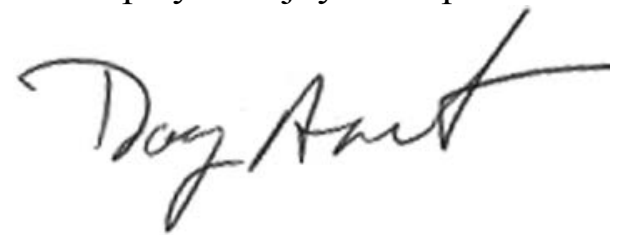

Douglas J. Arent

Executive Director, JISEA 


\section{Preface}

This report was developed with guidance from a cross-section of natural gas and electricity sector stakeholders. In 2011, JISEA convened a workshop with representatives from these organizations, some of whom also provided financial support for this work. That workshop resulted in identifying several key analytical issues for natural gas in the electric power sector that need to be addressed. Research, analysis, and writing were performed independently by the authors, with editorial oversight by JISEA. This study has been extensively peer reviewed. Findings, content, and conclusions of this study are the sole responsibility of the JISEA study team. JISEA provides objective information so that decision makers can make informed choices, but does not make its own policy recommendations.

Although the sponsoring organizations provided invaluable perspective and advice to the study group, individual members may have different views on one or more matters addressed in the report. The sponsoring organizations were not asked individually or collectively to endorse the report findings nor should any implied endorsement by the sponsoring organizations be assumed.

\section{Authors}

Jeffrey Logan, Lead Author, Introduction and Chapters 4 and 5. Mr. Logan is a Senior Research Analyst and Section Supervisor at NREL. He has two decades of experience in clean energy policy analysis and project management, including prior appointments at the International Energy Agency in Paris and the Congressional Research Service in Washington, D.C.

Garvin Heath, Ph.D., Lead Author, Chapter 1. Dr. Heath is a Senior Scientist at NREL. He has 18 years of experience evaluating environmental impacts of energy technologies, both at NREL and the U.S. Environmental Protection Agency.

Elizabeth deLone Paranhos, J.D., Lead Author, Chapter 2. Ms. Paranhos is a Senior Research Fellow, Energy Innovation Initiative, University of Colorado Law School. She is an environmental attorney specializing in clean air and energy policy with ten years of experience. For the past three years, her practice has focused primarily on natural gas activities.

William Boyd, J.D., PhD, Co-Author, Chapter 2. Mr. Boyd is an associate professor at the University of Colorado Law School, where he teaches and conducts research in the areas of energy law and regulation, environmental law, and climate change law and policy. He is a fellow of the Renewable and Sustainable Energy Institute and serves as the University of Colorado representative on the JISEA program committee.

Ken Carlson, Ph.D., Lead Author, Chapter 3. Dr. Carlson is an Associate Professor in Civil and Environmental Engineering, Colorado State University, and the Director of the Colorado Energy Water Consortium (http://cewc.colostate.edu). He has 16 years of experience in energy and water engineering issues.

Jordan Macknick, Co-Author, Chapter 3. Mr. Macknick is an Energy and Environmental Analyst at NREL. He has seven years of experience evaluating international energy and water issues. 
Contributing NREL Authors: Noah Fisher, James Meldrum, Ph.D. (Chapter 1); Courtney Lee (Chapter 3); Anthony Lopez, Trieu Mai (Chapter 4).

Study Director: Lynn Billman. Ms. Billman is a Senior Research Analyst and Section Supervisor at NREL. She has many years of experience leading major projects at NREL in all areas of renewable energy and energy efficiency.

\section{Suggested Citation}

Joint Institute for Strategic Energy Analysis (JISEA). 2012. Natural Gas and the Transformation of the U.S. Energy Sector: Electricity. Logan, J., Heath, G., Paranhos, E., Boyd, W., Carlson, K., Macknick, J. NREL/TP-6A50-55538. Golden, CO, USA: National Renewable Energy Laboratory. 


\section{Acknowledgments}

The JISEA institutional partner universities-University of Colorado-Boulder, Colorado School of Mines, Colorado State University, Massachusetts Institute of Technology, Stanford University - provided instrumental support throughout this study effort. The engagement of our partner universities made this report possible.

The authors would like to thank the following individuals for research assistance: Ashwin Dhanasekar, Shane White, and Xiaochen Yang of Colorado State University; Katie Patterson and Jamie Cavanaugh of the University of Colorado Law School; and Carolyn Davidson, Andrew Martinez, Patrick O’Donoughue, and Vanessa Pineda of the National Renewable Energy Laboratory.

We would like to thank the following organizations for their support and steering committee engagement: British Petroleum; Colorado Oil and Gas Association; ConocoPhillips; DB Climate Change Advisors; Electric Power Research Institute; Encana Natural Gas Inc.; ExxonMobil; GE Energy; National Grid; Southern Company; UBS Global Asset Management; and Xcel Energy.

This report has been reviewed in draft form by individuals chosen for their diverse perspectives and technical expertise. These reviews serve to make this report as technically sound as possible, and they ensure that the report meets institutional standards for objectivity, evidence, and responsiveness to the study scope.

We wish to thank the following individuals for their participation in the review of this report:

- Dan Bakal, Monika Freyman, Joe Kwasnik, and Ryan Salmon, CERES, and also for their engagement on the steering committee

- Dr. Stanley Bull, Midwest Research Institute

- Mr. Christopher Carr, J.D., C2E2 Strategies LLC

- Dr. Christa Court, Midwest Research Institute at the National Energy Technology Laboratory

- Dr. David Kline, NREL

- Dr. Joel Swisher, Stanford University and Rocky Mountain Institute

- Dr. Sue Tierney, The Analysis Group

- Dr. Azra Tutuncu, Colorado School of Mines

- Dr. Michael Webber, University of Texas

- Mr. Jeffrey Withum, Midwest Research Institute at the National Energy Technology Laboratory

- Dr. Mark Zoback, Stanford University

Additionally, the authors are grateful for review of Chapter 1 by Tim Skone of the National Energy Technology Laboratory and by Joe Marriott of Booz Allen Hamilton, who supports the National Energy Technology Laboratory. Prof. Hannah Wiseman of the Florida State University College of Law and Jon Goldstein with The Environmental Defense Fund also provided insightful review and helpful comments on the regulatory chapter. Daniel Steinberg of the National Renewable Energy Laboratory also provided key suggestions for the modeling scenarios. 


\section{Table of Contents}

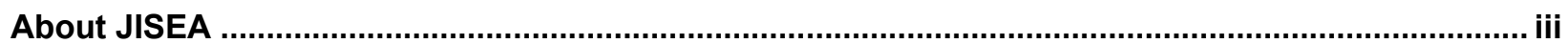

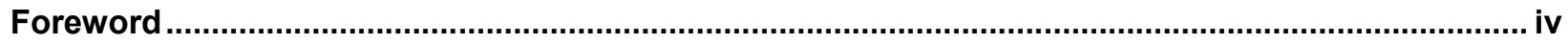

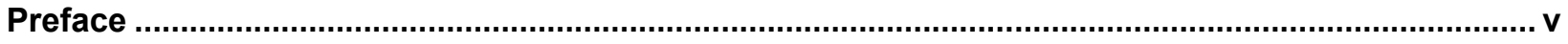

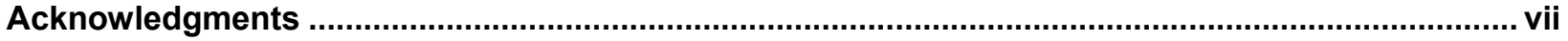

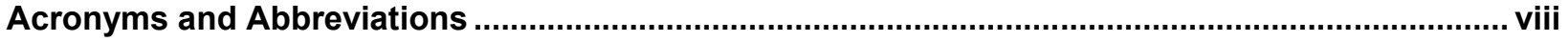

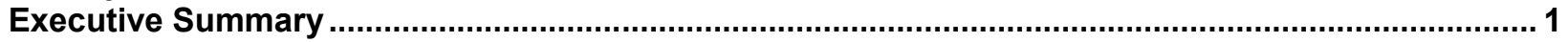

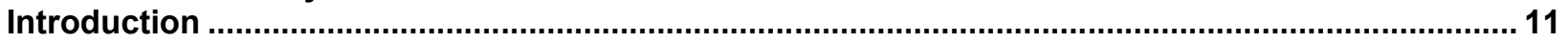

1 Life Cycle Greenhouse Gas Emissions from Barnett Shale Gas Used to Generate Electricity 16

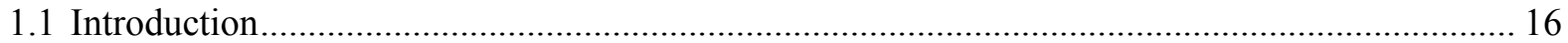

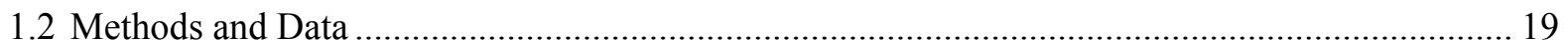

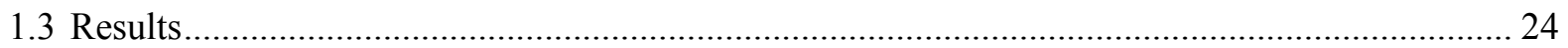

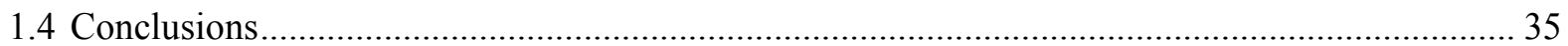

2 Regulatory Framework Governing Unconventional Gas Development.................................... 38

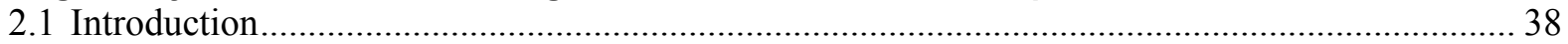

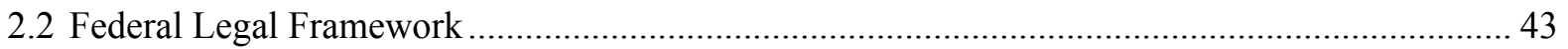

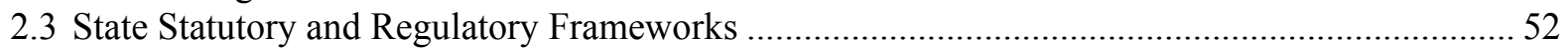

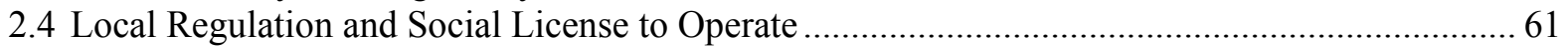

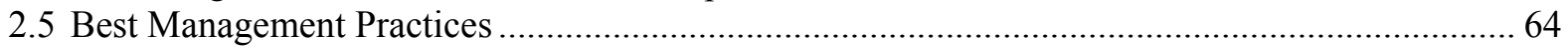

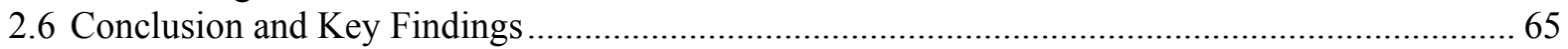

3 Key Issues, Challenges, and Best Management Practices Related to Water Availability and

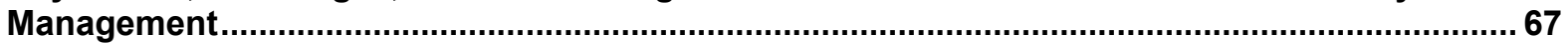

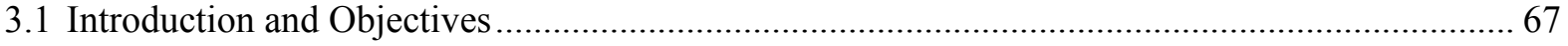

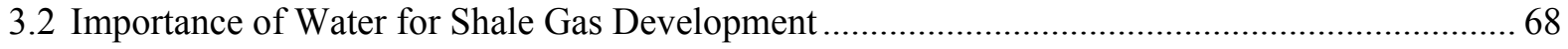

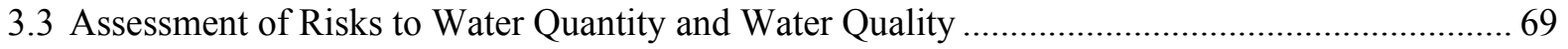

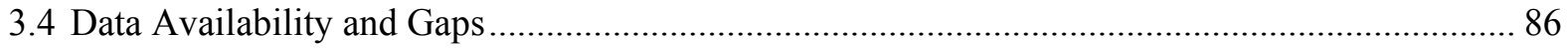

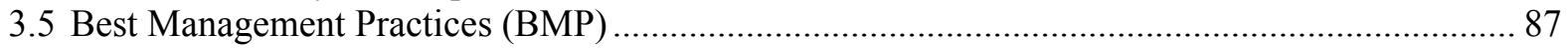

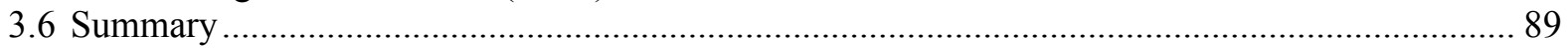

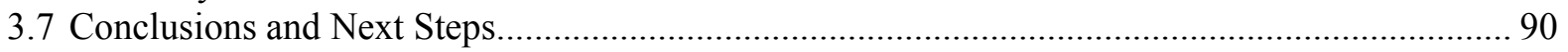

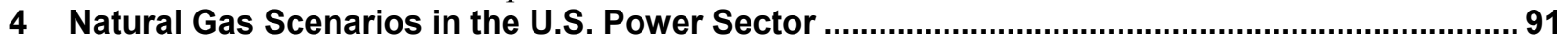

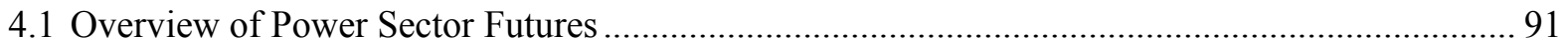

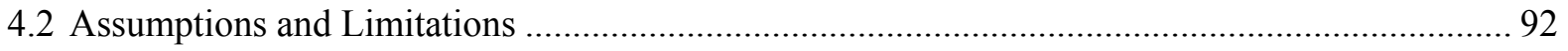

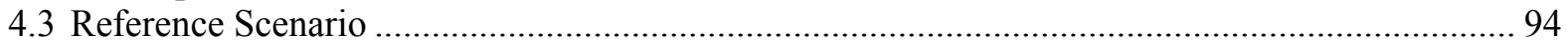

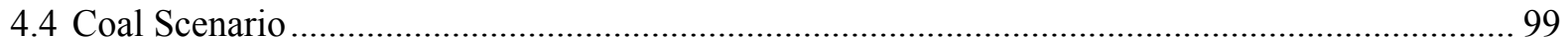

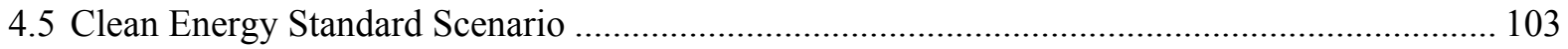

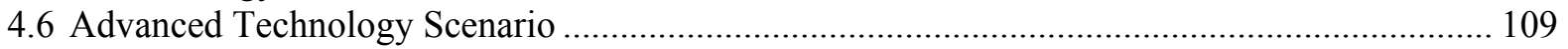

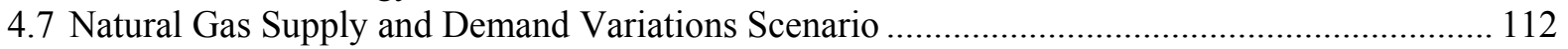

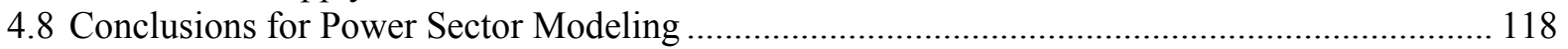

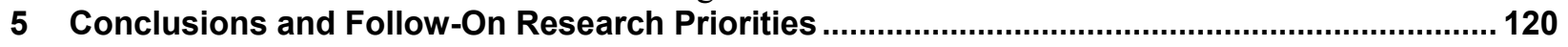

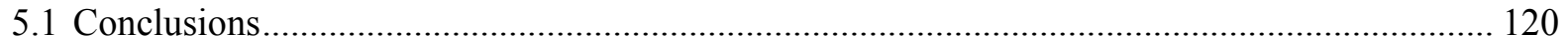

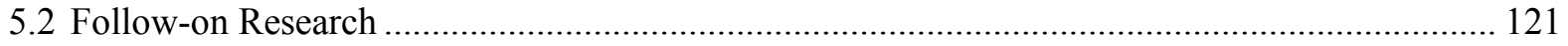

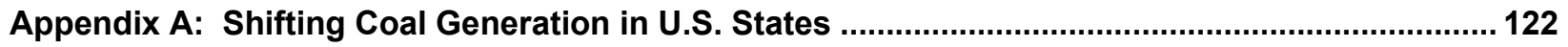

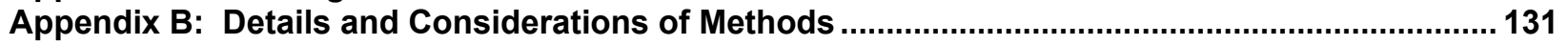

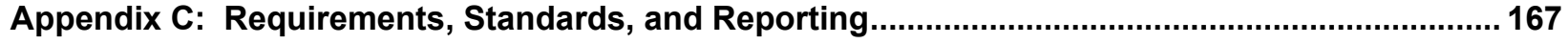

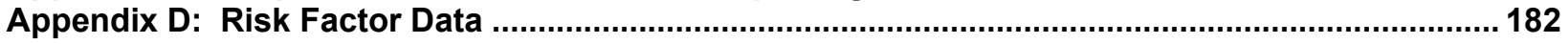

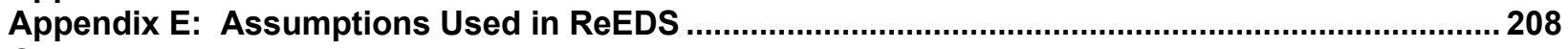

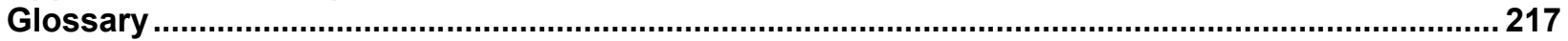

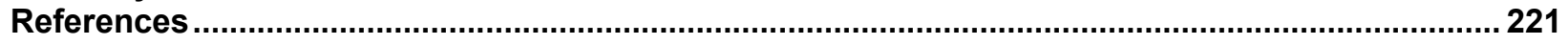




\section{Executive Summary}

Domestic natural gas production was largely stagnant from the mid-1970s until about 2005. Planning had been under way by the early 2000 s to construct about 40 liquefied natural gas import terminals along the U.S. coasts to meet anticipated rising demand. However, beginning in the late 1990s, advances linking horizontal drilling techniques with hydraulic fracturing allowed drilling to proceed in shale and other formations at much lower cost. The result was a slow, steady increase in unconventional gas production.

As the technology improved and spread, domestic shale gas output began to increase rapidly, such that by 2008 commentators began to routinely speak of a shale gas "boom." Today, shale gas accounts for about $30 \%$ of total U.S. natural gas production-up from only $4 \%$ in $2005-$ helping to make the United States the largest producer of natural gas in the world by 2009 . Within a decade, the question of how much more dependent the country would become on natural gas imports had been replaced by how much the U.S. gas supply will affect the economics and geopolitics of energy around the globe.

Although the long-term outcome of the shale gas revolution is far from decided, significant shifts are already apparent in U.S. power markets. In that context, low-price natural gas has had the greatest impact to date on generation by coal power plants. Since 2008, coal's share of annual generation has declined from $48 \%$ to $36 \%$ as of August 2012. This switch from coal to natural gas, combined with growth of renewable energy generation, has led to a reduction of carbon dioxide emissions in the U.S. power sector of about 300 million tons-equivalent to $13 \%$ of total power sector emissions in 2008 .

It remains unclear, however, whether natural gas will continue to exert such a dramatic impact on the power sector and the overall U.S. economy. If natural gas prices continue to stay at, or near, historically low levels, then a self-correction in the shale gas boom may occur. Due to price concerns, some companies have shifted away from drilling for dry gas and instead are focusing on plays that provide natural gas liquids. The ongoing debate is about what price is needed for unconventional natural gas production to be more sustainable over the medium term. As an example, analysis from Range Resources indicates that New York Mercantile Exchange prices of \$4-\$6/MMBtu are needed at the vast majority of plays to generate adequate returns on investment. ${ }^{1}$ Other factors - including "use it or lose it" lease terms, reserve filings with the Securities and Exchange Commission, and the amount of natural gas liquids that can be recovered - all play a role in continuing investment decisions. But, for now, natural gas markets are still widely acknowledged as oversupplied, and storage facilities held record high amounts of gas as of mid-2012.

Hydraulic fracturing has received negative attention in many parts of the country-especially those areas not accustomed to the oil and gas industry - due to real and perceived environmental and social concerns. Water use and contamination, air pollution, greenhouse gas (GHG) emissions, and truck traffic are among the concerns that have strained the social license to operate, and they have been the subject of multiple national and international reports and

\footnotetext{
${ }^{1}$ Specifically, a 12\% internal rate of return (IRR). The reference to this analysis appears in Ventura, J., 2012. "Uncovering Tomorrow's Energy Today," presentation at the Goldman Sachs Global Energy Conference 2012. 10 January 2012. Slide 11. Accessed 9 June 2012.
}

1 - Executive Summary 
continued dialogue. Field practices associated with unconventional natural gas production have evolved rapidly in some regions, either from new regulatory requirements or voluntary company practices. These field practices are still evolving, can be uneven across regions, and are sometimes controversial. At the same time, consolidation within the industry is shifting production from smaller to larger companies.

The Joint Institute for Strategic Energy Analysis (JISEA) designed this study to address four related key questions, which are a subset from the wider dialogue on natural gas:

1. What are the life cycle greenhouse gas (GHG) emissions associated with shale gas compared to conventional natural gas and other fuels used to generate electricity?

2. What are the existing legal and regulatory frameworks governing unconventional gas development at federal, state, and local levels, and how are they changing in response to the rapid industry growth and public concerns?

3. How are natural gas production companies changing their water-related practices?

4. How might demand for natural gas in the electric sector respond to a variety of policy and technology developments over the next 20 to 40 years?

\section{Major Findings}

Although the questions analyzed in this report are interlinked to a certain extent, they have specific requirements in terms of analysis methodologies and associated stakeholders. The key findings are presented very briefly as follows:

- Greenhouse gas emissions: Based on analysis of more than 16,000 sources of airpollutant emissions reported in a state inventory of upstream and midstream natural gas industry, life cycle greenhouse gas emissions associated with electricity generated from Barnett Shale gas extracted in 2009 were found to be very similar to conventional natural gas and less than half those of coal-fired electricity generation.

- Regulatory trends: The legal and regulatory frameworks governing shale gas development are changing in response to public concerns and rapid industry changes, particularly in areas that have limited experience with oil and gas development. All of the states examined in this study have updated their regulatory frameworks to address the opportunities and challenges associated with increasing unconventional natural gas production.

- Water management: Many regions evaluated in this study are making greater use of innovative water management practices to limit real and perceived risks. However, a lack of reliable, publicly available water usage and management data — such as total water withdrawals, total wells drilled, water-recycling techniques, and wastewater management practices - currently hinders efforts to develop appropriately flexible and adaptive best management practices. Recent studies have documented a number of management practices related to the chemical makeup of fracking fluids, impacts on local freshwater, and on-site wastewater management that may be appropriate in many locations. 
However, to date, no public studies have been published on cost-benefit, risk-mitigation potential, or the transferability of practices from one shale play to another.

- Electric power futures: A number of different future electric power scenarios were analyzed to evaluate both the implications of shale gas development and use, and various policy and technology changes. These scenarios include power plant retirements, advances in generation technologies, federal policies to reduce greenhouse gas emissions, and variations in natural gas supply and demand. We find that natural gas use for power generation grows strongly in most scenarios.

\section{Life Cycle Greenhouse Gas Emissions from Barnett Shale Gas Using Air-Quality Inventory Data}

A national debate over life cycle GHG emissions ${ }^{2}$ from shale natural gas erupted in 2011 after a study was released stating that shale gas had equivalent or even greater GHG emissions than coal. ${ }^{3}$ Since then, a number of other published, peer-reviewed studies have included contrary findings, ${ }^{4}$ although data limitations and methodological variability make conclusive statements problematic about the "real" GHG emission profile.

For Chapter 1, the study team conducted original research on life cycle GHG emissions associated with natural gas production in the Barnett Shale play in Texas. This estimate leverages high-resolution empirical data to a greater extent than previous assessments. The data sources and approach used in this study differ significantly from previous efforts, providing an estimate valuable for its complementary methodological approach to the literature.

The authors used inventories from 2009 that tracked emissions of regulated air pollutants by the natural gas industry in the Barnett Shale play. The Texas Commission on Environmental Quality (TCEQ) collected and screened these inventories. These data cover the characteristics and volatile organic compound (VOC) emissions of more than 16,000 individual sources in shale gas production and processing. Translating estimated emissions of VOCs into estimates of methane and carbon dioxide emissions was accomplished through the novel compilation of spatially heterogeneous gas composition analyses.

Major findings from this analysis of life cycle GHG emissions include:

- Electricity generated using a modern natural gas combined-cycle turbine combusting Barnett Shale gas produced and processed in 2009 has life cycle GHG emissions ranging between 420 and 510 grams carbon dioxide-equivalent emissions per kilowatt-hour (g

\footnotetext{
${ }^{2}$ GHG emissions considered within a life cycle assessment (LCA) include those from the "fuel cycle" of natural gas, which includes activities from well drilling and completion, through production, processing, and transport to the power plant, as well as from the life cycle of the power plant, which includes construction and decommissioning of the power plant and combustion of the fuel. Results are normalized per unit of electricity generated $(\mathrm{kWh})$. See Figure 7 within Chapter 1 and the surrounding text for further description of the scope of this LCA.

${ }^{3}$ Howarth, R. W., R. Santoro, and A. Ingraffea. 2011. "Methane and the greenhouse gas footprint of natural gas from shale formations." Climatic Change Letters, DOI: 10.1007/s10584-011-0061-5 (http://www.springerlink.com/content/e384226wr4160653/fulltext.pdf).

${ }^{4}$ These studies include Burnham et al. 2012; Jiang et al. 2011; Skone et al. 2011; Stephenson et al. 2011; Hultman et al. 2011.
} 
$\mathrm{CO}_{2} \mathrm{e} / \mathrm{kWh}$ ) generated, depending on assumed lifetime production of a well, with a central estimate of about $440 \mathrm{~g} \mathrm{CO}_{2} \mathrm{e} / \mathrm{kWh}$ - similar to levels reported in the literature from conventional natural gas and less than half that typical for coal-fired electricity generation (Figure 1). ${ }^{5}$ Comparisons to conventional natural gas and coal are achieved through harmonization of 200 published estimates of life cycle GHG emissions for those two technologies. ${ }^{6}$ Harmonization is a meta-analytical process that makes consistent the assumptions and methods between LCAs.

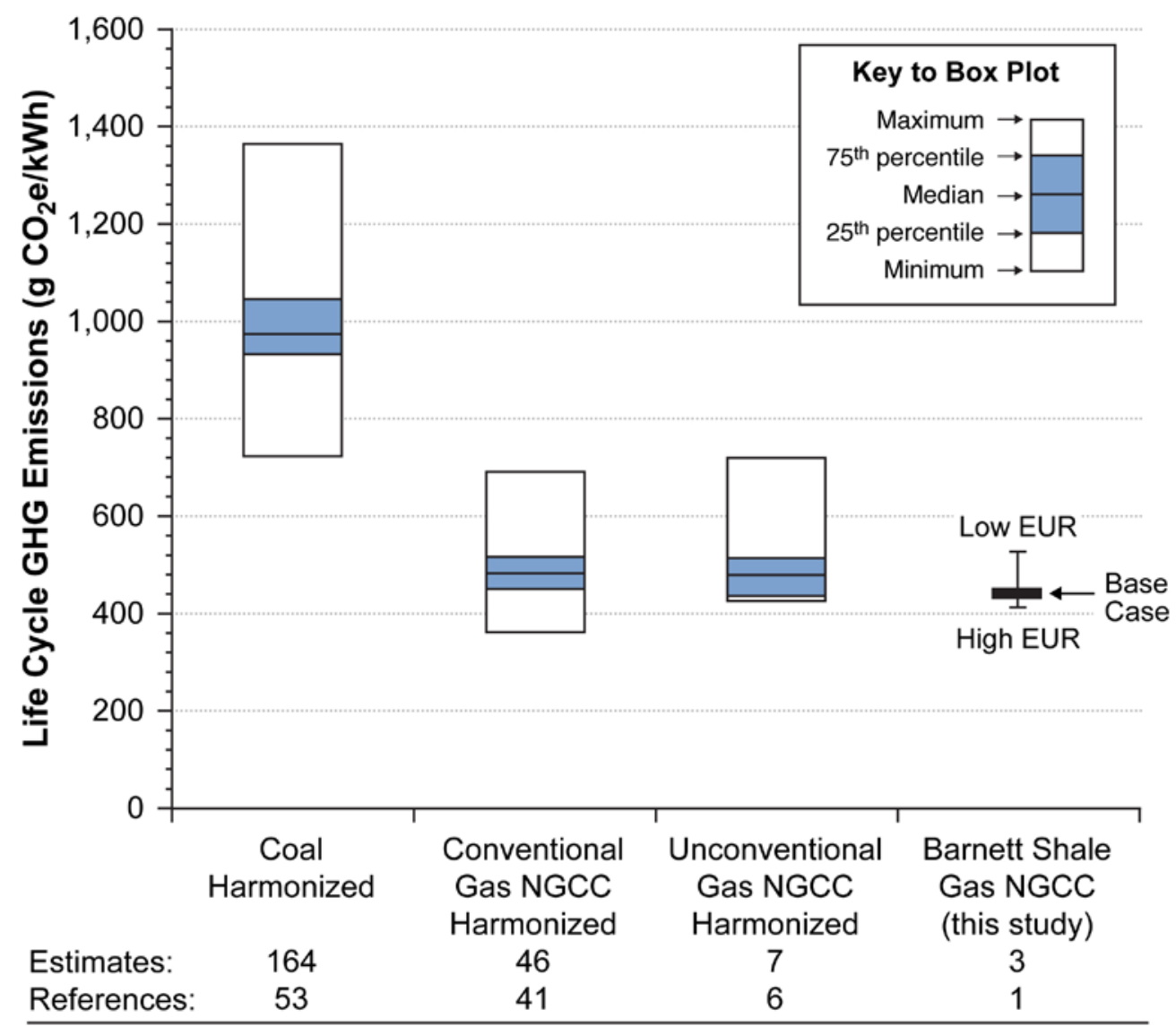

Figure 1. Estimate of life cycle GHG emissions from 2009 Barnett Shale gas combusted to generate electricity in a modern natural gas combined-cycle (NGCC) turbine compared to previously published estimates for unconventional (mostly shale) gas, conventional natural gas, and coal after methodological harmonization.

Notes: EUR = estimated ultimate recovery, or lifetime production; NGCC = natural gas combined-cycle turbine

\footnotetext{
${ }^{5}$ The results reported here do not include emissions associated with liquids unloading, a process that the natural gas industry recently reported as applicable to both conventional and unconventional wells, but without direct evidence for the Barnett Shale play. (See: Shires and Lev-On (2012).)

However, inclusion of these emissions would not qualitatively change our findings.

${ }^{6}$ See Whitaker et al. 2011 and O'Donoughue et al. 2012 for systematic review and harmonization of published estimates of life cycle GHG emissions from coal-fired and conventional natural gas-fired electricity generation, respectively.
} 
- An estimated $7 \%$ to $15 \%$ of life cycle GHG emissions from electricity generation (mean $=9 \%$ ) are from methane emissions throughout the fuel cycle of Barnett Shale gas (well pre-production activities through transmission), mostly from venting during completion and workover, and from the natural gas transmission pipeline network.

- GHG emissions result from many sources throughout the production and use of natural gas. Based on our analysis, more than half can be characterized as sources with potentially controllable leakage - for instance, from tanks or vents. Another $20 \%$ are combustion sources, which also have some emission control opportunities. Remaining sources, called fugitive emissions, are more challenging to control because of their dispersed nature.

- An estimated 1.5\% of Barnett Shale produced gas is emitted to the atmosphere before reaching the power plant, much of which is potentially preventable, with an additional $5.6 \%$ of produced gas consumed along the process chain as fuel for different types of engines. Based on the estimated methane content of this produced gas and average assumed lifetime production of a well, this equates to a central estimate of leakage rate across the life cycle of $1.3 \%$ methane volume per volume of natural gas processed.

- Chemical composition of produced gas varies considerably within the Barnett Shale area such that at the county level, estimates of GHG emissions differ significantly from those based on composition averaged at a higher spatial resolution (play or nation). Variability in gas composition has implications for the understanding of emission sources and the design of regulatory emission control strategies.

\section{A Changing Regulatory Framework for Unconventional Gas Production}

Chapter 2 examines the main federal, state, and local regulatory frameworks that govern unconventional natural gas development. Specifically, it focuses on requirements related to water withdrawals used for hydraulic fracturing, disclosure of chemicals used in hydraulic fracturing fluids, setbacks for wells, baseline water monitoring of surface water resources or water wells, well-construction standards, "green" or "reduced emission" completions, storage of waste in closed-loop systems, and the disposal of produced water. It also examines state compliance monitoring and enforcement capabilities, and the efforts by some local governments in key gasproducing states to limit - and, in some cases, ban — unconventional gas development. Major findings include the following:

- There is a trend toward more regulation at all levels of governance, but there has been a corresponding increase in regulatory fragmentation and differentiation at state and local levels. Better coordination and policy alignment among regulators can help to reduce risks to industry and the public of regulatory fragmentation-including uncertainty, delays, gaps, and redundancies across jurisdictions. Improved communication and sharing of information among regulators at all levels of government and across jurisdictions, as well as increased transparency in the form of publicly available data from industry, would help address regulatory fragmentation and inform regulatory development tailored to specific geographic and geologic characteristics.

- Compliance monitoring and enforcement varies across states, with significant implications for the efficacy of regulations, as well as public confidence. Increased public disclosure of voluntary information — as well as public disclosure of violations, 
enforcement actions, and company compliance-would increase transparency, offer opportunities to highlight the compliance records of leading companies who have demonstrated a commitment to safe natural gas production, and help address public concerns.

- There is a significant range in the environmental performance of operators in the industry, with some operators performing at a level that goes beyond existing regulations and other operators falling short. There is an evolving portfolio of recommended practices emerging from across the stakeholder community; these practices can complement and supplement regulations.

- The varied state and local approaches to regulation can provide important opportunities for learning and innovation regarding substantive rules, the role of best practices, and compliance and enforcement. Regulators might consider adopting performance-based standards, rather than freezing today's "best management practices" into prescriptive rules that could become outdated.

\section{Management Practices in Shale Gas Production: Focus on Water}

Chapter 3 addresses current water usage and water management practices at shale gas development sites and discusses risks to water availability and quality. We evaluated publicly available water usage data from six shale plays throughout the United States. When data were available, we conducted statistical analyses from a randomized sample of wells in each play to gauge current estimates of water usage per well. In addition, data were collected on current wastewater management techniques and volumes associated with managing produced water from wells along with the returned fracking fluids. Lastly, in addition to analyzing current industry practices, we evaluated how water usage, well number, and water management techniques have evolved over time, indicating that water risk and management issues in the future may differ from historical issues. Natural gas exploration and production has significant spatial variability in community and environmental issues, current practices, and regulations. Therefore, JISEA is also publishing the water-related results of this study in a web-based GIS format.

The three primary water impact risks are: regional resource depletion due to use of fresh water during hydraulic fracturing, surface water degradation, and groundwater degradation. Impact risks to water resources vary geographically based on three considerations: 1) where the water comes from, 2) what water use and management practices are followed on site for hydraulic fracturing, and 3) how and where produced water and frac flowback water are treated and/or disposed.

Major findings from this analysis of water impacts include the following:

- Risks to regional freshwater depletion depend on a variety of factors, including water use per well, total number of wells, water recycling rates, and regional water availability. Analysis of use data for four of the six regions from 2007 to 2011 indicated average water use per well ranges from 1.1 to 4.8 million gallons, with a multi-region average of 3.3 million gallons. The total magnitude of water usage depends on the number of wells drilled, which has increased in most regions from 2007 to 2011. In the Eagle Ford play, for example, gas wells increased from 67 in 2009 to 550 in 2011. Total freshwater usage depends on water recycling rates, which may vary greatly depending on location. In

6 - Executive Summary 
2011, the highest rates of recycling were reported in Pennsylvania, where 37\% of produced water and $55 \%$ of frac flowback water were recycled, representing nearly 200,000 gallons per well, or $4 \%$ of average water use per well in Pennsylvania. Total impacts on regional freshwater resources can be evaluated by comparing total freshwater uses with estimates of regional freshwater availability.

- Wastewater management practices vary regionally and show different trends from 2008 to 2011. In Pennsylvania, $80 \%$ of produced water and $54 \%$ of frac flowback water was treated through surface water discharge in 2008, whereas in 2011, less than $1 \%$ of produced water and frac flowback was treated through surface water discharge. In 2011, centralized disposal facilities and recycling are the primary wastewater management methods, accounting for $80 \%$ of produced water volumes and $99 \%$ of frac flowback volumes. In Colorado, surface water discharge of both produced water and frac flowback volumes has increased from $2 \%$ in 2008 to $11 \%$ in 2011 . Management of produced water and frac flowback through onsite injection pits and evaporation ponds have remained the dominant practices from 2008 to 2011 , representing $72 \%$ and $58 \%$, respectively.

Treatment at a centralized disposal facility has increased from $26 \%$ to $31 \%$ from 2008 to 2011. The management and transport of produced water and frac flowback water is considered to be the stage at which spills and leaks are most likely.

- A lack of reliable, publicly available water usage and management data hinders comprehensive analyses of water risks. Data are not publicly available for total water withdrawals, total gas wells drilled, flowback volume per well, water recycling techniques, wastewater management, and other management practices for many regions. These data would assist in developing appropriately flexible and adaptive best management practices. Certain resources - such as the State Review of Oil and Natural Gas Environmental Regulations (STRONGER) and FracFocus - have greatly increased public access to information about risks of hydraulic fracturing; however, further efforts would be beneficial.

- A variety of best management practices are currently being employed in different regions, but there is industry uncertainty over transferability, cost-effectiveness, and risk mitigation potential. Recent studies have documented a number of water-related management practices related to the chemical makeup of fracking fluids (disclosure of additives, minimizing or switching to more benign additives, baseline water quality testing), the impacts on local freshwater (measuring and reporting of volumes, water recycling, use of non-potable or non-water sources), and onsite wastewater management techniques (use of closed-loop drilling systems, elimination of flowback and freshwater mixing in open impoundments, use of protective liners at pad sites) that may be appropriate in many locations. However, to date, there are no publicly available studies that have performed cost-benefit analyses, evaluated the risk-mitigation potential of each strategy, or analyzed practices that could be transferred from one shale play to another.

\section{Modeling U.S. Electric Power Futures Given Shale Gas Dynamics}

In Chapter 4, the study evaluates different electric power scenarios that are influenced by natural gas availability and price, as well as other key policy, regulatory, and technology factors. Many of the scenarios examine sensitivities for the estimated ultimate recovery (EUR) of gas fields. High-EUR corresponds to more abundant and inexpensive natural gas compared to Low-EUR. 
Major findings from the electric sector analysis include the following:

- Natural gas demand by the power sector would grow rapidly - more than doubling from the 2010 level by 2050 - in the Reference, or baseline, scenario. ${ }^{7}$ Figure 2 illustrates the range of natural gas power generation in all scenarios. The main Reference scenario suggests that natural gas would replace coal as the predominant fuel for electricity generation. Attributes of this baseline scenario include rising power demand, stable greenhouse gas emissions, and slowly rising electricity prices that reflect natural gas availability and prices. By 2050 , in the Reference scenario, gas could represent from $28 \%$ to $38 \%$ of power-sector generation compared to the 2010 portion of $20 \%$.

- In a coal retirement scenario, natural gas, and wind to a lesser extent, replaces coal-based generation. Our modeling results indicate no impact on power sector reliability from 80 GW of coal retirements by 2025 on an aggregate scale, although additional detailed dispatch modeling is needed to evaluate localized impacts. National average retail electricity prices in the retirement scenario increase by less than $2 \%$ in 2030 compared to the baseline.

- Under a clean energy standard (CES) scenario, U.S. power sector carbon dioxide emissions would decrease by $90 \%$ between 2010 and 2050, with a corresponding 6\%$12 \%$ increase in average retail electricity prices, including transmission build-out that ranges from 3 to 6 times more than the Reference scenario (measured in million MWmiles). Among the CES sensitivity scenarios, large quantities of variable renewable energy and flexible gas generation work synergistically to maintain system reliability requirements.

${ }^{7}$ A Reference scenario serves as a point of comparison with other alternative scenarios. The Reference assumes a fairly static view of the future, so it, and all alternative scenarios, should not be considered forecasts or predictions of the future. 


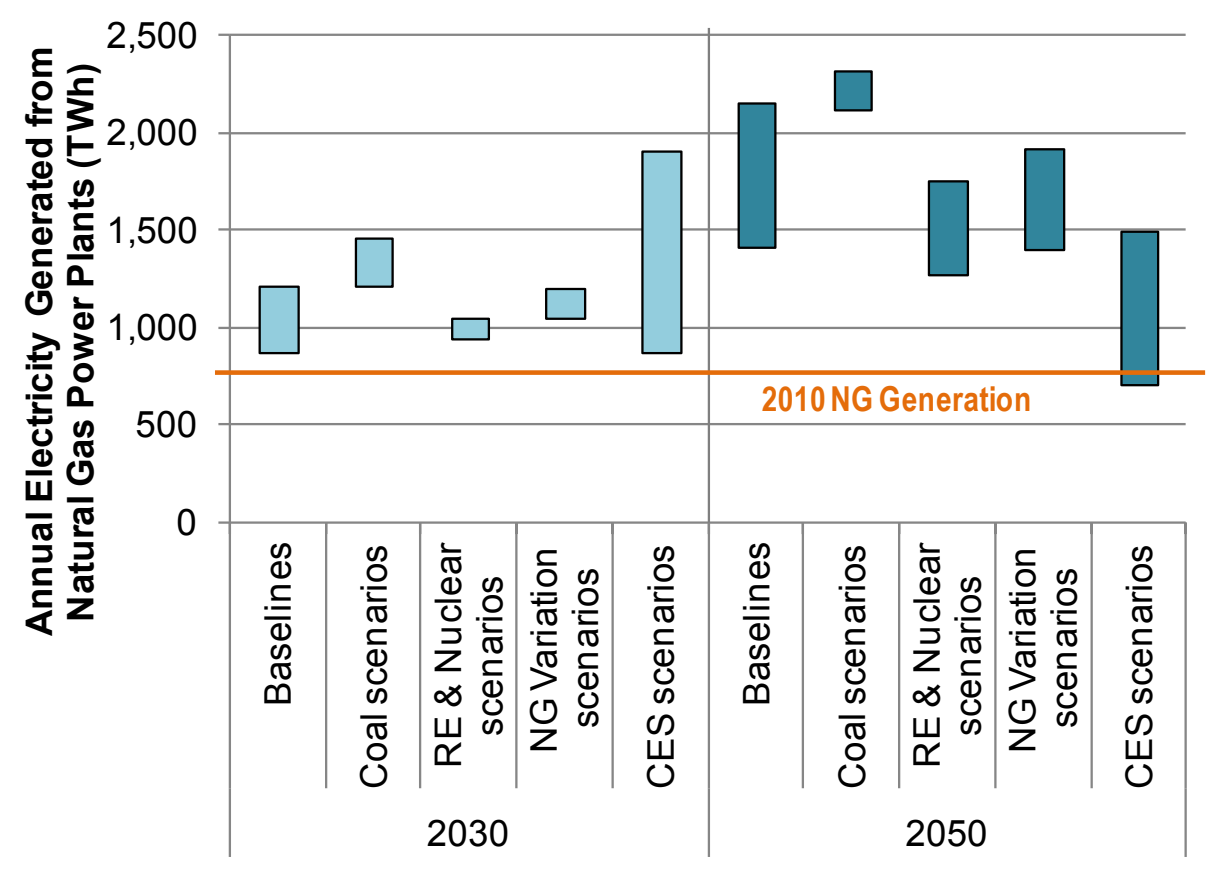

Figure 2. Range of electricity generated from natural gas plants in the scenario analysis

- Advances in generation technologies can have a significant impact on estimated carbon emissions, electricity diversity, and prices. For example, nuclear capital costs would need to decline by half, while gas prices remain relatively high (as simulated in the low-EUR assumption), for the nuclear generating option to compete economically with other options. Wind and solar electricity could more than double by 2050 compared to the Reference scenario with continued improvements in the cost and performance of these technologies. Likewise, continued improvements in production techniques for unconventional natural gas production could enable natural gas to continue to grow market share.

- We consider a range of potential incremental costs associated with operating practices that could better address some of the public concerns in the production of unconventional natural gas. Some of these options include recycling larger amounts of frac flowback water, reducing methane releases to the atmosphere, setting well locations further from potentially sensitive communities, and assuring consistent use of best practices or regulations in well drilling and completions. Sensitivities in incremental costs were evaluated from $\$ 0.50 / \mathrm{MMBtu}$ to $\$ 2 / \mathrm{MMBtu}$. For example, additional costs of \$1/MMBtu associated with some or all of these several dozen operating practices would lead to a $17 \%$ reduction in gas use for power generation by 2050 compared to the Reference scenario; however, gas-fired generation still more than doubles from the 2010 level.

- A "dash-to-gas" scenario, where other sectors of the economy increase natural gas demand by 12 billion cubic feet per day by 2030, would likely result in higher domestic gas prices and lead to a roughly $20 \%$ reduction in power sector natural gas use by 2050 compared to the Reference scenario in that year, but still nearly twice the level used in 2010. Additional research is needed to understand how natural gas prices respond to rising demand in the new natural gas environment. 
The rapid expansion of shale gas has created dynamic opportunities and challenges in the U.S. energy sector. How long the ascendancy of natural gas in the electric sector will last will be a function of a wide variety of market and policy factors. The story of unconventional gas is evolving rapidly, and in some cases, unexpectedly. Robust and up-to-date analysis will remain critical to informing the key decisions that must be made by all types of stakeholders in the energy and environmental arenas. 